Gerión. Revista de Historia Antigua

ISSN: 0213-0181

\title{
"Un olor balsámico propio de las resinas aromáticas de Oriente". La supuesta acta del desvendamiento de la momia egipcia conservada en el Museo de Anatomía de la Universidad Complutense de Madrid
}

\author{
Miguel Ángel Molinero Polo ${ }^{1}$
}

Recibido: 13 de octubre de 2017 / Aceptado: 13 de diciembre de 2017

Resumen. Hace dos décadas se anunciaba el "hallazgo" en Madrid de la momia de una princesa egipcia, hija de Ramsés II. La fuente para esa identificación era la supuesta acta redactada durante el proceso de desvendamiento durante la década de 1880. Si bien la determinación fue puesta en duda en medios académicos desde el primer momento, no se había analizado el texto que la sustentaba. Los objetivos de este artículo son: dar a conocer una lectura crítica del acta, de la que se concluye que fue escrita décadas después de la sesión; precisar datos relacionados con la fecha y actuaciones durante el acto; y exponer la identificación de la adolescente momificada que proporcionó E. Toda. Él fue quien la trajo a España, junto a una colección de cráneos egipcios donada -como la momia-a la institución donde tuvo lugar el acto, la Facultad de Medicina de San Carlos, y sus datos son la única referencia conocida de la procedencia de estos restos. Las rectificaciones permiten contextualizar la sesión en la incipiente Egiptología española del siglo XIX.

Palabras clave: Egipto antiguo; Eduard Toda i Güell; Deir el Medina; TT1; Isis; Sennedjem.

\section{[en] "A balsamic smell typical of the oriental aromatic resins". The alleged "unwrapping act" of the Egyptian mummy kept in the Museum of Anatomy of the Universidad Complutense of Madrid}

\begin{abstract}
Two decades ago the "discovery" in Madrid of the mummy of an Egyptian princess, a daughter of Ramesses II, was announced. The basis for this identification was the alleged act drafted during the process of its unwrapping during the 1880s. Although this recognition was questioned in academic media from the outset, the text supporting it had not yet been analysed. The aims of this article are threefold: to present a critical reading of the supporting act, which was probably written several decades after the session; to clarify information relating to the date and procedures of the unwrapping; and to identify the young mummified woman provided by E. Toda. It is him who brought the body to Spain, along with a collection of Egyptian skulls that he donated to the Faculty of Medicine of San Carlos -beside the mummy- where the unwrapping took place, and his data are the only known reference of the origin of these remains. Rectifying some of the statements made at the time of the "rediscovery" allows the session to be contextualised in the incipient Spanish Egyptology of the nineteenth century.

Keywords: ancient Egypt; Eduard Toda i Güell; Deir el Medina; TT1; Isis; Sennedjem.
\end{abstract}

Sumario. 1. Fecha de la sesión de desvendamiento y solemnidad del acto. 2. Desarrollo de la sesión. 3. Autoría, cronología y finalidad del acta. 4. Contextualización y conclusiones. 5. Anexo. 6. Referencias bibliográficas.

\footnotetext{
1 Universidad de La Laguna.
}

E-mail: mmolipol@ull.edu.es 
Cómo citar: Molinero Polo, M. Á. (2018): "Un olor balsámico propio de las resinas aromáticas de Oriente". La supuesta acta del desvendamiento de la momia egipcia conservada en el Museo de Anatomía de la Universidad Complutense de Madrid, en Gerión 36/1, 247-264.

En 1995, E. Llagostera Cuenca presentó en el VII Congreso Internacional de Egiptólogos una comunicación acerca de la momia egipcia que se conserva, desvendada, en el Museo de Anatomía de la Universidad Complutense de Madrid. Junto al estudio anatómico, a partir de radiografías realizadas por él mismo, añadía una serie de comentarios históricos sobre la identidad de la persona momificada. Afirmaba que se trataba de una princesa llamada Isis, hija de Ramsés II y cantora de Amón. ${ }^{2}$ Su fuente para esa identificación era -en sus propias palabras- el acta oficial redactada por un secretario durante la sesión de desvendamiento, conservada en la misma institución que la momia. ${ }^{3}$ Esta habría sido traída a España por Eduard Toda i Güell, vicecónsul español en Egipto entre 1884 y 1886, quien reunió una amplia colección de objetos egipcios durante esos años.

Tras la aparición de la noticia en la prensa española, durante varias semanas, periódicos y radios entrevistaron al autor del descubrimiento. ${ }^{4}$ En cada intervención este iba aportando nuevos datos, con frecuencia mal comprendidos por los periodistas y nunca contrastados. ${ }^{5}$

La identificación fue pronto cuestionada por J. Padro i Parcerisa ${ }^{6}$ y rechazada con argumentos convincentes por $\mathrm{M}^{\mathrm{a}} \mathrm{C}$. Pérez Díe, directora de la Sección de Oriente Próximo y Egipto en el Museo Arqueológico Nacional (en adelante: MAN). Ella argumentaba que E. Toda "nunca identificó esta momia como perteneciente a una hija de Ramsés II"7 en ninguna de sus publicaciones, a pesar de hablar de este rey en varios textos e incluso dedicar un libro a su figura. ${ }^{8}$

El autor de este artículo presentó en un congreso celebrado en Lieja, en 2015, una comunicación en la que mostraba los datos que el propio E. Toda dio a conocer sobre la momia, desconocidos en el momento del redescubrimiento. Sin embargo, ese estudio inicial mostró la necesidad de disponer de más información sobre los años egipcios del vicecónsul, por lo que la publicación definitiva fue retrasada hasta completar ese análisis previo..$^{9}$ Esto ha permitido reunir una serie de datos que entran en contradicción con los que proporcionaba Llagostera. Dicho investigador basa sus conclusiones no solo en el acta que habría escrito un secretario durante el desvendamiento sino también en otras fuentes que no especifica. El acceso al manuscrito del $\operatorname{acta}^{10}$ y la documentación nueva sobre $\mathrm{E}$. Toda que ha aparecido en las últimas dos

\footnotetext{
Llagostera Cuenca 1995; véase también Llagostera Cuenca 1998 y 2003.

Llagostera Cuenca 1995, 111: “Authenticity Act of the Egyptian Mummy”. En esta publicación afirma que se conservaba en los archivos, mientras que en una entrevista posterior asegura que se hallaba en la vitrina misma donde se conservaba la momia (Castel Ronda 1996, 10). El hecho de que estuviera protegida en una vitrina indicaría un cuidado en su conservación que no se corresponde con la idea de que fue "descubierta" por este investigador.

4 Un ejemplo de tono mesurado es la noticia redactada por J. Antón en El País, 13 de septiembre de 1995.

5 El mismo Llagostera se hace eco de los comentarios más extremos aparecidos en los periódicos durante la quincena de días previos, en el curso de una larga entrevista: Castel Ronda 1996.

6 El País, 18 de septiembre de 1995.

7 Pérez Díe 1996, 7.

8 Se refería a Toda i Güell 1886a.

9 Molinero Polo 2017.

10 Agradezco al Prof. Dr. José Antonio Sánchez Sánchez, director del Museo de Antropología Forense de la Universidad Complutense de Madrid, el permiso para acceder a la lectura del acta.
} 
décadas ${ }^{11}$ permiten no solo reforzar la crítica que publicó entonces Pérez Díe a la identificación de la momia como la de una princesa egipcia sino desmontar la fiabilidad del texto mismo. La transcripción de esta "Copia del acta de autenticidad de la momia egipcia" 12 se presenta como anexo al final del presente artículo para facilitar el acceso a su información. Además, creemos haber identificado la segunda fuente - no explicitada- de Llagostera, una biografía escrita por E. Toda de su amigo, el doctor Josep Ribera y Sans, en la que rememora el acontecimiento cuarenta y cinco años después de que tuviera lugar. ${ }^{13}$

La documentación presentada en este texto proporciona también información, aunque poco relevante, sobre la llegada a Madrid de un conjunto de cráneos que fueron donados por E. Toda al Colegio de San Carlos. Puede tratarse de alguno de los que hoy se conservan en el Museo de Antropología Forense, en la misma Facultad de Medicina. Momia y cabezas son los elementos del Egipto antiguo identificados en el Patrimonio cultural de la Universidad Complutense de Madrid (en adelante: UCM).

\section{Fecha de la sesión de desvendamiento y solemnidad del acto}

El acta conservada en la Facultad de Medicina afirma que la conferencia y la sesión de desvendamiento que le siguió tuvieron lugar "en el curso de 1884 a 1885", mientras que Llagostera precisa -sin especificar fuente- que fue en octubre de 1884. En ese mes y año, E. Toda no podía asistir a ningún acto en Madrid, pues estaba en Egipto. El vicecónsul español residió dos años seguidos en El Cairo sin desplazarse ni a España ni a ningún otro país durante ese periodo. El verano de 1884 lo pasó en Alejandría, en la playa de Ramla. Varios testimonios escritos por él mismo dejan constancia de ese traslado estacional: su diario, los artículos de periódico escritos en esos meses y fechados en esa ciudad, e incluso la descripción de su casa en su libro A través del Egipto. ${ }^{14}$ Por otros documentos -los artículos de periódico que se hacen eco de la sesión desde su anuncio en los días previos, durante la tarde misma en que se desarrolló y en los días posteriores- la conferencia y desvendamiento parcial de la momia tuvieron lugar el 24 de octubre de $1886 .{ }^{15}$ También existen testimonios del mismo E. Toda para confirmar día, mes y año, como un artículo publicado solo unas semanas más tarde. ${ }^{16}$

11 Sobre el centenar de artículos periodísticos publicados por E. Toda durante sus dos años de estancia en Egipto y en los meses siguientes, "redescubiertos" recientemente para la Egiptología, véase Molinero Polo 2015. Sobre los documentos del diplomático conservados en el archivo del CSIC, véase Toda i Güell s.d. Para otras fuentes de información, véase Molinero Polo 2017, 293-295.

12 Este es el nombre completo del documento. El término "copia" no se menciona en las publicaciones de Llagostera, pero se puede leer en la fotografía que se presenta en Castel Ronda 1996, 11.

13 Toda i Güell 1930, 27-29. Llagostera cita casi textualmente algún párrafo de este libro durante la entrevista publicada en Castel Ronda 1996, 12.

14 En las páginas del diario de E. Toda se puede leer que dejó Ramla el 29 de septiembre. Desde el 7 de octubre empezó una visita sistemática a las mezquitas del Cairo antiguo (Toda i Güell 2008, 80-81). Sus descripciones se convirtieron en artículos de periódico que envió a El Globo y a La Renaixença. Diari de Catalunya (cf. Molinero Polo 2015 y 2017, 292, notas 1 y 2, 294-296, 299-300 y apéndice). En cuanto a la casa en la que pasó el verano, véase Toda i Güell 1889, 56-57. Un texto de E. Toda $(1930,27)$ que parece haber leído Llagostera (a juzgar por sus alusiones al Dr. Ribera) menciona 1886, pero debió de desestimar esta fecha.

15 Por ejemplo, en: La Época, domingo 24 de octubre de 1886; La República, 26 de octubre de 1886. La lista de referencias de la prensa diaria en esas dos semanas puede alcanzar una cifra superior a la veintena.

16 Toda i Güell 1886b, 267 y 269. 
Sin embargo, en octubre de 1884 había tenido lugar un acto con un enorme impacto en la sociedad madrileña y española que estuvo relacionado con la Egiptología. La conferencia de apertura del curso académico en la Universidad Central fue pronunciada por Miguel Morayta y Sagrario, profesor de Historia de ese mismo centro. El tema era la civilización egipcia antigua. Su texto, conocido porque fue publicado en una versión más extensa, estaba muy bien estructurado y basado en bibliografía puesta al día. Junto a ese tema, expresaba también una crítica muy dura a la presencia de la Iglesia Católica y sus dogmas en la educación española y, en particular, en la investigación universitaria. Sus críticas a las fechas bíblicas y sus dudas respecto a la historicidad del Antiguo Testamento eran un intento de separar ciencia y religión, a semejanza de procesos similares que se estaban produciendo en otros contextos académicos europeos. La situación derivó en conflicto cuando, unos días después del acto, un obispo condenó al conferenciante y un representante del partido conservador inició una recogida de firmas para su expulsión del centro. En contestación, los estudiantes salieron de las clases en apoyo del profesor, lo que fue duramente reprimido, iniciando un movimiento de protestas más amplio. Así, la Egiptología académica española tiene la rara distinción de haber provocado, en su nacimiento, manifestaciones estudiantiles, arrestos policiales, heridos $\mathrm{y}$, finalmente, el cierre de todas las universidades del país por tres meses. ${ }^{17} \mathrm{El}$ acontecimiento y su fecha tuvieron que seguir siendo recordados por bastante tiempo. Algunos artículos de prensa que recogen la noticia del desvendamiento de la momia reflejan todavía ecos, dos años después, de aquella conferencia en el Paraninfo del antiguo Noviciado. ${ }^{18}$

Algo sorprendente es que Llagostera menciona octubre como el mes en que tuvo lugar el evento, lo que es correcto, pero ese dato no está especificado en el acta conservada en la Complutense ni en el libro de E. Toda que creemos que aquel utilizó también como base de su información. Desconocemos si tuvo una tercera fuente o simplemente dedujo el mes al pensar que se trataba de la apertura del curso.

Una segunda afirmación de este investigador sobre la sesión no encuentra apoyo ni en el "acta de autentificación" ni en la documentación coetánea, aunque está mencionada por E. Toda en su libro de $1930:{ }^{19}$ que tuviera lugar durante la reapertura del Aula Magna. ${ }^{20}$ El edificio del Real Colegio de Cirugía de San Carlos, después Facultad de Medicina, había sido concluido en 1834. ${ }^{21}$ Sin embargo, su decoración fue, efectivamente, renovada en los años previos a la conferencia. El final de los trabajos había sido firmado por el decano de la Facultad, el arquitecto y el pintor, en mayo de $1885,{ }^{22}$ por lo que es presumible que en esa fecha las obras ya estarían concluidas. En octubre de 1885 se documenta una visita de la familia real para "ver las pinturas

\footnotetext{
Molinero Polo 2011.

18 El Liberal, 25 de octubre de 1886, 2: "El primer hombre vino al mundo 4000 años antes de Cristo, según el libro sagrado de los hebreos; pero en Egipto había ya un Estado organizado y poderoso 9.000 años antes de la misma fecha", con un error evidente de fechas, pero con el recuerdo de la idea esencial del discurso de M. Morayta. Compárese con el carácter sarcástico del artículo publicado en La Ilustración Católica, 5 de noviembre de 1886, $1-2$, en el que la momia desvendada vuelve a hablar, pero es en realidad la criada del conserje del anfiteatro de San Carlos.

19 Toda i Güell 1930, 29.

20 La lectura de los textos ingleses podría resultar ambigua y "opening” comprenderse como la apertura del año académico. Sin embargo, en las entrevistas en español Llagostera usa el término: "inauguración” (Castel Ronda 1996, 10). E. Toda $(1930,29)$ lo recuerda como "nou Amfiteatre (...) estrenat pera la ocasió".

21 Saiz Carrero 2009, 191.

22 Reyero 1986, 180.
} 
con que ha enriquecido el techo del Anfiteatro el artista Señor [Ramón] Padró [y Pedret]". ${ }^{23}$ Resulta así muy dudoso que se esperase un año adicional para su reapertura, en octubre de 1886. Por el contrario, si esta hubiera tenido lugar coincidiendo con la conferencia y actuación sobre la momia, los numerosos periódicos que recogen el acto no habrían dejado de mencionarlo.

Otra cuestión que levanta una cierta suspicacia hacia el "acta de autentificación" es la mención a las autoridades presentes. Se cita al Ministro de Instrucción Pública y al Ministro de Estado. Pero en la España de la Restauración la enseñanza pública quedaba bajo la responsabilidad del Ministro de Fomento, quien, efectivamente, estuvo presente en la sesión, y dentro de su Ministerio, de la Dirección General de Instrucción Pública, cuyo titular también asistió. Tampoco había entonces un Ministro de Estado. Resulta así sorprendente que en el documento que -según Llagosterase redactó durante la sesión, el secretario diera unos títulos a los dos ministros asistentes que no les correspondían. Aún más asombroso es que no se mencione a los otros miembros del Gobierno que presidieron el acto, junto a los dos ya mencionados, y que se recogen en los periódicos que se hicieron eco de la sesión: ${ }^{24}$ el Ministro de Ultramar, el rector de la Universidad, el entonces diputado (después de haber ejercido los cargos más altos del estado) Cánovas del Castillo y el Marqués de Molins, seguramente como representante de las Academias.

\section{Desarrollo de la sesión}

La sesión se desarrolló en dos partes. Se inició con una conferencia pronunciada por E. Toda y esta fue seguida por la apertura del ataúd y el desvendamiento de la momia que contenía. Salvo en el orden de esas dos partes, que coinciden con la información proporcionada por la prensa de esos días, la mayoría de los detalles que menciona el acta presentan diferencias con las otras fuentes. La conclusión -idéntica a la que se deduce de los problemas señalados en el apartado anterior- es que la afirmación de Llagostera de que este documento fue escrito durante la sesión misma, como si se tratara de la certificación levantada por un secretario, es una interpretación errónea.

El acta empieza por mencionar la colocación del ataúd sobre la mesa de mármol. No se señala si fue antes de iniciarse el acto o si fue introducida a la vista de los asistentes. Sin embargo, los periodistas proporcionan la imagen de que la momia estaba ya expuesta cuando se inició la sesión:

Allí, sobre la mesa de blanco mármol en que de ordinario se colocan los cadáveres, veíase un paquete largo, de un metro y 20 centímetros próximamente, cubierta una de sus extremidades, la más abultada, por una mascarilla y el resto por cierta envoltura de cartón extrañamente dibujada. ${ }^{25}$

23 "El techo del anfiteatro de San Carlos", La Época, 20 de octubre de 1885, 3. La fecha del periódico citada en Reyero 1986, nota 18, es errónea.

24 La relación de las seis personas que ocuparon los sillones del estrado puede leerse, por ejemplo, en La Época de 24 de octubre de 1886.

25 El Liberal, 25 de octubre de 1886, 2. Otro texto coincidente: "Delante de la presidencia, en la mesa de mármol (...), estaba cuidadosamente envuelta la momia. (...) El cónsul, Sr. Toda, ocupó una mesita al lado de la momia”, en El Día, 24 de octubre de 1886, 1. 
Las fuentes coinciden en el programa general de la conferencia, aunque los temas y el orden en que se trataron difieren ligeramente. Sin embargo, esto no puede ser utilizado como argumento en ningún sentido, pues es lógico que de los diversos asuntos explicados, cada oyente recordase o dejara por escrito aquellos que le resultasen más llamativos. Si aceptásemos la narración de La Época, el conferenciante habría dividido su conferencia en tres partes: hallazgo del sepulcro -hay que sobreentender que se trata del que contenía la momia-, idea que tenían los egipcios de la eternidad y procedimiento que se empleaba en las momificaciones. La prensa menciona también una afirmación significativa, que es la procedencia precisa del cuerpo: la tumba descubierta a comienzos de febrero de ese mismo año en Deir el Medina, ${ }^{26}$ es decir, la que hoy clasificamos como TT 1, a nombre de Sennedjem. Resulta sorprendente que el acta no recoja un dato tan importante si fue escrita en el momento en que se pronunciaba la conferencia.

El resto del documento se centra -salvo en un par de párrafos en que se desvía hacia comentarios ajenos al tema principal- en el desvendamiento mismo. La primera actuación habría sido la ruptura de los sellos que cerraban el ataúd. La momia, sobre la mesa del anfiteatro, aparecería cubierta por tres cartonajes, que quedan descritos: uno sobre la cabeza, otro sobre el pecho y el tercero sobre abdomen y extremidades. A partir de los jeroglifos, E. Toda dedujo ante el auditorio que se trataba de una sacerdotisa. Después se descubrió un lienzo "compuesto por una serie de bandaletas" cuyos extremos estaban sujetos por alfileres. Seguidamente se vio el sudario. Por último surgió la momia. Y, "una vez terminada la sesión fue entregada" al catedrático de Anatomía, Dr. Federico Olóriz y Aguilera, quien la estudió y determinó edad, caracteres antropométricos y causa de la defunción. Analizaremos cada una de estas fases del desvendamiento.

Ningún periódico menciona la apertura del ataúd ni la circunstancia excepcional -recogida en el acta- de que, al abrirlo, "los restos exhalaban un olor balsámico propio de las resinas aromáticas de Oriente”. Es extraño que los periodistas dejasen de mencionar ambos detalles, en especial el segundo. Podría argumentarse que ellos se hallaban a cierta distancia, en el anfiteatro, y no les llegarían los aromas, pero sería también extraño que los que estaban más cerca del cuerpo no lo señalaran a los asistentes y estos lo transmitieran a sus lectores. Por otra parte, el acta parece dar a entender que el ataúd era abierto por vez primera desde su descubrimiento, pues habla de la ruptura de sus sellos, ${ }^{27}$ pero esto es también imposible. El Service de Conservation des Antiquités había sido creado tres décadas antes de la conferencia madrileña para preservar el patrimonio egipcio. E. Toda había participado durante el invierno previo en el viaje al Alto Egipto que organizaba cada año esta institución. En el curso de esa inspección arqueológica se habría descubierto la momia -junto a las de otros miembros de su familia-si su procedencia de la TT 1 es cierta. En esa situación todos los ataúdes se abrían y se inspeccionaba su contenido, como sabemos que se hizo con los de la tumba de Sennedjem, pues los documentos de ese momento mencionan las momias que guardaban. Es inconcebible pensar que el Service hubiera permitido la salida de la colección Toda con un contenedor sellado del que no se hubiera verificado su contenido. Además, el ataúd no podría proceder de esa cámara de enterramiento si el acta es precisa en recordar que estaba muy deteriorado por la carcoma. Si los insectos xilófagos hubieran atacado uno de los ataúdes de la TT 1,

"Una solemnidad científica", La Época, 24 de octubre de 1886, 3.

Donde el acta induce a entender esa circunstancia, Llagostera lo afirmaba abiertamente $(2003,735)$. 
los demás se habrían visto afectados en idéntica medida. Como los que proceden con seguridad de ella se conservan en buen estado, el que llegó con el cuerpo a Madrid tuvo que tener otro origen. ${ }^{28}$

Tras describir los cartonajes, el acta señala que por "su magnificencia (...) y la traducción de los jeroglíficos egipcios que se observaban, el Sr. Toda deducía que se trataba de una sacerdotisa, hija de Sesostris y por lo tanto princesa egipcia". El texto deja suponer que el vicecónsul español era capaz de leer y traducir los textos egipcios a medida que aparecían. Sin embargo sus conocimientos de jeroglíficos debían de ser muy limitados. Un año después de la conferencia emitió un informe en el que consideraba auténticas las inscripciones del falso sepulcro de Tarragona, que parecen garabatos infantiles y no proporcionan ninguna lectura coherente. ${ }^{29} \mathrm{La}$ prensa de esos días es coincidente en señalar que la identidad que le dio E. Toda fue la de "una niña de once años llamada Isis, y era cantatriz de Ammon (sic) en los templos de Tebas"; algún medio da también su cronología: época de Ramsés IV. ${ }^{30}$ Hay que suponer que los signos que recogían el nombre y cargos de la difunta habían sido leídos previamente, cuando fue extraída de la tumba, por los egiptólogos del Service o deducidos por los objetos del ajuar. El nombre de la niña no está mencionado en el acta, pero aparece en la biografía del doctor Ribera, ${ }^{31}$ donde debió de encontrarlo Llagostera, aunque no lo explicita.

Surge también la duda acerca de dónde aparecían escritos el nombre y los títulos. En el acta da la impresión de que es en los propios cartonajes. Uno solo de los periódicos menciona este momento de la sesión y parece proporcionar la misma información: "y el pecho y el vientre estaban cubiertos por otra tela con inscripciones en que se consigna el nombre del cadáver y categoría a que perteneció, y varios collares pintados" ${ }^{32}$ Pero es imposible que fuera sobre unos cartonajes si la momia procede de la TT 1. Unas pocas semanas después de la sesión, E. Toda publicaba un artículo que debe de recoger, ampliado y reestructurado, el texto de la conferencia. Concluye con el hallazgo de la tumba de Sennedjem y la extracción de las momias y el ajuar. En ese apartado final, él mismo afirma la procedencia de la momia que había sido objeto del desvendamiento. Y el artículo se ilustra con una composición en la que se combinan escenas de la decoración de la cámara con sendas imágenes de una momia cubierta por cartonajes y ya sin ellos (Fig. 1) ${ }^{33}$ Esta segunda es la que se conserva en la Facultad de Medicina, por lo que puede deducirse que la revestida es la misma antes de la conferencia. Pero esos cartonajes no son ramésidas, que es la cronología de la TT 1 y de su contenido, sino ptolemaicos. Es decir, o la momia no es de la tumba de Sennedjem o los cartonajes son un añadido para hacer más llamativa la sesión. Los alfileres que, según el acta, sujetaban los extremos de las vendas ("parecidos a los que hoy se usan para pruebas y antes para sujetar la ropa colgada") son otro ele-

28 Sobre los ataúdes, véase Mahmoud 2011, 17 y 40.

29 Esta situación ya había sido mencionada por Pérez Díe $(1996,7)$ al comentar los acontecimientos de la ceremonia del desvendamiento. Sobre las circunstancias que llevan a E. Toda a escribir este memorial véase Molinero Polo - Redondo Villanova 2014; sobre el conjunto de falsificaciones egipcias aparecidas en Tarragona durante el s. XIX, véase Marcos Alonso - Pons Mellado 1996.

30 La Época, 24 de octubre de 1886, 3. El mismo nombre, sin los datos de su cargo y del reinado en el que vivió, puede verse en noticias de otros diarios durante varias semanas: El Correo Militar, 25 de octubre de 1886, 3; La República, 29 de octubre de 1886, 1-2; La Correspondencia de España, 31 de octubre de 1886, 1-2; La Época, 1 de diciembre de $1886,2$.

31 Toda i Güell 1930, 28.

32 La Época, 24 de octubre de 1886, 3.

33 Toda i Güell 1886b. 


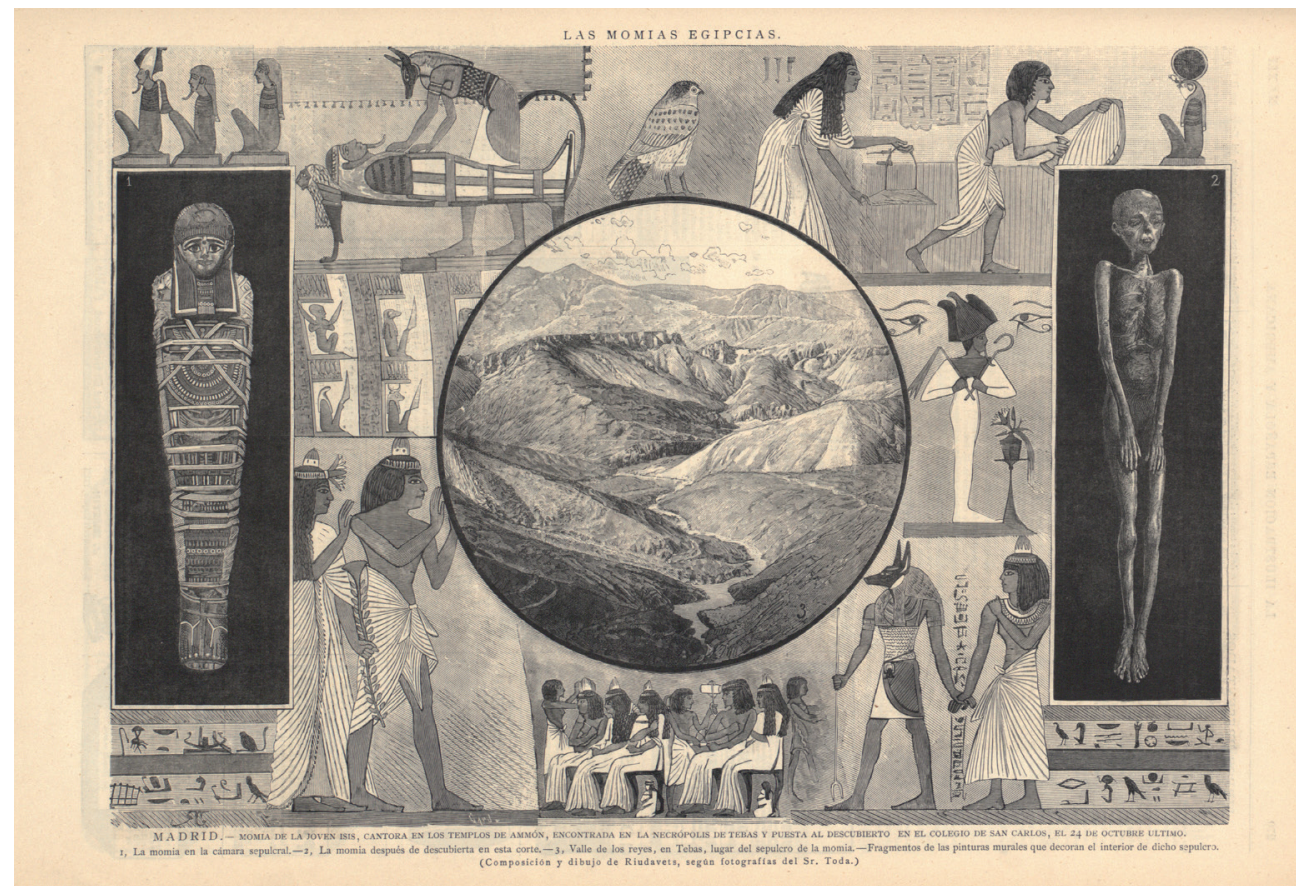

Figura 1. Ilustración de J. Riudavets para el artículo publicado por E. Toda que debe de recoger el texto, más o menos retocado, de su conferencia en la sesión de desvendamiento de la momia (Toda i Güell 1886b, 269).

mento incongruente. En el Egipto antiguo se usaban tiras estrechas de tejido atadas en horizontal para consolidar el conjunto, no alfileres. Puede deducirse que estos elementos fueron añadidos para evitar que se aflojara el vendaje y sugieren una intervención moderna en la preparación de la momia para el transporte desde alguno de los distintos lugares por donde pasó o para su exhibición.

Una única fuente parece indicar que había una tela - un sudario- envolviendo los vendajes, lo que habría sido la situación normal según los conocimientos actuales sobre la preparación de momias en el Reino Nuevo: ${ }^{34}$

Quitaron primero la careta dorada y dejaron descubiertos los cartones que ocupaban en el pecho el lugar que ocuparon las joyas. (...) Quitaron la envoltura de tela cosida, impregnada de vino de palmera, y enseguida las largas bandas que rodeaban el cuerpo. ${ }^{35}$

El acta no menciona ese tejido exterior, lo que una vez más podría tomarse como un ejemplo de imprecisión, pero en este aspecto la situación es compleja. En el grabado que ilustra el artículo de E. Toda antes citado se ven las vendas directamente bajo los cartonajes, como si, efectivamente, no se conservara sudario. Sin embargo, una colección de antigüedades aragonesa conserva dos fragmentos de lino procedentes de esta sesión. Su propietario, Enrique de Otal y Ric, conocido del conferenciante pues ambos habían coincidido desempeñando cargos diplomáticos en China, los calificó como su-

34 Sobre el modelo de vendaje durante el Reino Nuevo, véase Ikram - Dodson 1998, 157-160.

35 El Día, 24 de octubre de 1886, 1. 
dario en la nota que escribió para mantener el recuerdo de su procedencia. ${ }^{36}$ Podría deducirse que él los recibió como tal en ese momento. Las medidas de los fragmentos no pueden ayudar a resolver la duda de si formaban parte del sudario o podrían corresponder a las vendas. Esta segunda opción no puede descartarse pues se conocen vendajes de esa anchura e incluso mayores.

La afirmación de que el tejido estuviera impregnado de un vino de palmera -y no de otra materia- no podía ser reconocida a simple vista en una sesión como la que nos ocupa. En aquella época no se hacían análisis a materiales arqueológicos que identificaran esos componentes. Este dato solo podía derivar de fuentes textuales leídas por el orador. ${ }^{37}$

Una información del acta que recoge Llagostera, y en este caso parece correcta, se refiere al "triste destino de las vendas. (...) Toda (...) las corta en trocitos y los va entregando a todos los asistentes al acto", ${ }^{38}$ una circunstancia que no está mencionada en ninguna otra fuente coetánea. El Museo de Anatomía no conserva ningún fragmento pero los dos antes mencionados, pertenecientes al Palacio de los Barones de Valdeolivos en Fonz, Huesca, testimonian que se procedió de ese modo. El esmero que los egipcios antiguos ponían en la calidad de los tejidos y el cuidado vendaje de las imágenes divinas y momias contrasta con el descuido con que la Egiptología ha tratado estos materiales. Desde que se iniciaron el desvendamiento académico y las excavaciones arqueológicas las vendas fueron sistemáticamente desechadas hasta fechas muy recientes. ${ }^{39} \mathrm{E}$. Toda y sus colaboradores siguieron, así, el modelo de actuación de ese momento.

Para terminar con el tema de los olvidos incomprensibles del acta, en ella no se menciona que el desvendamiento no fue concluido. Según la prensa, descubiertos rostro y pies, los doctores no levantaron el resto del sudario que cubría el cuerpo. Se adujeron motivos técnicos: el baño de natrón a que eran sometidos los cadáveres habría adherido las bandas al cuerpo, por lo que serían necesarias manipulaciones técnicas adicionales para poder retirarlo por completo. ${ }^{40}$

El acta termina con la referencia al estudio realizado a la momia por F. Olóriz y las conclusiones a las que este llegó. Es evidente que esto solo pudo escribirse cuando el estudio ya había sido concluido y, por tanto, después de terminada la sesión. En realidad, como veremos a continuación, el documento mismo muestra que no fue redactado en octubre de 1886.

\section{Autoría, cronología y finalidad del acta}

El acta no está firmada ni fechada, pero hay referencias en el propio texto que ayudan a precisar vagamente su autoría y, sobre todo, una fecha post quam.

La persona que redactó el documento estaba presente en la sala como colaborador: "pues tuve el alto honor de ser designado por el Sr. Decano para ayudar al descubrimiento de la momia". Era, por tanto, médico o todavía estudiante de Medicina. La prensa del día recoge los nombres de las tres personas que participaron junto al diplomático en la sesión, los doctores Calvo y Martín, Olóriz y Tapia. ${ }^{41}$ José Calvo y

\footnotetext{
Luque Talaván 2009, 113-115, 350-352. Agradezco a J. M. Galán Allué que me diera a conocer estos dos fragmentos. Herodoto (2.86) cita el vino de palma, aunque no en el proceso de vendaje sino en el lavado inicial del cadáver. Declaraciones recogidas en Castel Ronda 1996, 10.

Riggs 2014, en especial 19-32.

La Época, 24 de octubre de 1886, 3; La República, 26 de octubre de 1886, 2.

La República, 26 de octubre de 1886, 2.
} 
Martín era el decano de la Facultad, ${ }^{42}$ por lo que queda excluido como autor del documento. También hay que descartar a F. Olóriz, como se verá a continuación. Si el tercer facultativo ya era médico, entonces tendría que ser Tapia ${ }^{43}$ Pero cabe la posibilidad de que fuera alguien aún no licenciado, designado para una labor subalterna, y la prensa no recogiera su nombre.

Un segundo indicio para su identificación es que el autor dice haber participado también bajo la dirección de su maestro, Alejandro San Martín, en el embalsamamiento del novelista Manuel Fernández y González. Esta actuación tuvo lugar en la sede del Ateneo de Madrid, entre el 6 y 7 de enero de $1888^{44}$-año y medio después de la conferencia- y es mencionada por bastantes periódicos madrileños, en los que se citan los nombres de cuatro médicos: Salillas, Tous/Fons, Granados y San Martín. ${ }^{45}$ Ninguno coincide con los tres de San Carlos pero, como en el caso previo, si el autor del acta era todavía un ayudante, la prensa no lo citaría.

Una tercera información importante para esta pesquisa es que el traslado de la colección de cráneos de F. Olóriz se hizo cuando el autor del acta desempeñaba ya "su cargo", posiblemente en la Facultad de Medicina.

En una entrevista, Llagostera menciona a un "Federico Pombo, que levanta el acta", sin especificar cómo llega a conocer ese nombre, y de él dice más adelante que firmó el documento que se encontraba en la urna de cristal del Museo de Anatomía. ${ }^{46}$ Sin embargo, en la versión escaneada del original a la que ha tenido acceso el autor de este artículo no figura ninguna firma.

Dos referencias en el texto proporcionan pistas sobre la fecha de redacción del acta. La primera es que se habla de F. Olóriz como alguien que ya ha muerto, lo que se produjo en $1912 .{ }^{47}$ Y se añade que Julián de la Villa [y Sanz] había salvado lo que había podido de la colección de aquél e integrado la momia en el museo que él mismo había creado, en el segundo piso del gran anfiteatro (y, por tanto, todavía en Atocha, no en la Ciudad Universitaria). Como J. de la Villa fue nombrado catedrático de Anatomía Descriptiva de la Facultad de Medicina de Madrid en $1923,{ }^{48}$ esta es la fecha post quam para la redacción del "acta". Y, en realidad, teniendo en cuenta que se habla del museo creado -o rescatado- por este catedrático, habría que añadir algún año más, tiempo necesario para la elaboración de ese proyecto.

\section{Contextualización y conclusiones}

La primera conclusión evidente es que el acta no se escribió durante la sesión de desvendamiento, sino varias décadas después y recurriendo a los recuerdos personales de su autor, que no solo estuvo presente sino, según afirma el texto, colaborando en el

42 La Época, 24 de octubre de 1886, 3.

43 No hemos identificado su nombre y segundo apellido. No puede tratarse del conocido doctor Antonio García Tapia, pues este había nacido en Ayllón, Segovia, en 1875, por lo que no pudo participar en este acto once años después.

44 El escritor murió el 6 de enero y el día 7 se abría la capilla ardiente. La Época, 7 de enero de 1888, 1 y 3.

45 La Época, 6 de enero de 1888, 2; 7 de enero de 1888, 1 (aquí no se cita a Granados).

46 Frases en el contexto de una entrevista recogida en Castel Ronda 1996, 11 y 12.

47 Ficha en la relación de académicos de número de la Real Academia de Medicina: http://www.ranm.es/academicos/academicos-de-numero-anteriores/1021-1896-oloriz-y-aguilera-federico.html. Consultada: 23 de septiembre de 2017.

48 Ficha en la relación de académicos de número de la Real Academia de Medicina: http://www.ranm.es/academicos/ academicos-de-numero-anteriores/819-1948-villa-y-sanz-julian-de-la.html. Consultada: 23 de septiembre de 2017. 
acto. El recurso a la memoria explica los errores en la fecha, las autoridades presentes y numerosos detalles del desarrollo de la sesión. El propio nombre del acta adquiere sentido si se considera la circunstancia de una redacción muy posterior. A los coetáneos a la conferencia no era necesario señalarles que era la misma momia que se desvendó en el anfiteatro de San Carlos; por el contrario, sí sería imprescindible "autentificarla" si llevaba en la Facultad de Medicina ya varias décadas y no hubiera constancia fehaciente de su procedencia. El objetivo del acta, cuya redacción fue asumida por alguien que tenía, aparentemente, una cierta responsabilidad en la institución, era certificar que se correspondía con aquella que fue presentada en Madrid unas décadas atrás, al tiempo que desvelaba algunas de las circunstancias que la llevaron hasta la Facultad.

Idéntico problema presenta la rememoración de la sesión escrita por E. Toda para la biografía de su amigo J. Ribera. Parece recurrir a sus recuerdos y eso le lleva a dar noticias que no se confirman ni en la prensa coetánea a la sesión ni en los documentos de la venta de su colección. Por ejemplo, señala que esta contenía "vuyt momias complertas, intactas sas vestiduras de bandeletas perfumadas de natrón" (sic), ${ }^{49}$ cuando los varios inventarios conservados coinciden en señalar solo dos momias humanas (además de la infantil que donó a la Biblioteca Museu Victor Balaguer de Vilanova i la Geltrú); tal vez estaba contando también las de animales, que suman seis más, además de un pie. ${ }^{50}$ En consecuencia, los datos de este libro del diplomático que no pueden confirmarse por una segunda fuente han de ser tomados con precaución y rechazados -entendidos como problema de memoria- si entran en contradicción con testimonios más fiables.

Esta misma obra aporta información sobre una donación de cabezas momificadas egipcias hecha por el propio E. Toda con intermediación de J. Ribera a la misma institución donde se depositó la momia. Como en el ejemplo anterior, cabe preguntarse por la exactitud de sus recuerdos:

Al anar a Egipte en 1884 ens doná l'especial encárrech de recollir pera'l Museu de la Facultat de Medicina una colecció de cranis aborígenes lo més extensa posible, es a dir, cobrint desde las primeras epocas del Reys pastors fins a las darrerías de la decadencia dels Ptolomeos. Executárem la comissió portant a nostre retorn a Madrit una trentena d'exemplars que anaren a juntarse als nombrosos de la serie cuydada pel catedrátich doctor Frederich Oloriz, íntim company de Ribera. ${ }^{51}$

Una pequeña colección de cabezas de origen egipcio se conserva en la actualidad en el Museo de Antropología Forense de la Universidad Complutense, compuesta al menos de siete ejemplares. ${ }^{52}$ Teniendo en cuenta la dispersión de la colección de $\mathrm{F}$. Olóriz a su muerte, no puede extrañar que el número de ejemplares conservados en la Ciudad Universitaria no alcance la cifra recordada por E. Toda en 1930. Sin embargo, en los inventarios del diplomático conservados en el CSIC -y que el autor de este artículo había interpretado en un estudio previo como los del traslado de la colección desde Egipto a España- se incluye una entrada de solo cuatro cráneos ${ }^{53}$ Es-

\footnotetext{
Toda i Güell 1930, 28. Recuérdese que E. Toda escribía en un catalán prenormativo.

Archivo MAN, Expediente 1887/1. También hay un "trozo de carne" sin más especificación.

Toda i Güell 1930, 28.

Labajo González et alii 2011.

53 Toda i Güell s.d., 119, 127. Sobre los diversos inventarios de la colección y su interpretación, véase Molinero Polo 2017, 306.
} 
tos no figuran en el inventario de la colección vendida al MAN, por lo que podrían ser los que dice haber regalado al Museo de F. Olóriz. El problema es la disparidad en la cifra entre ambos documentos: de treinta en uno a cuatro en otro. Este número aún podría reducirse más si hubiera que incluir en él las dos cabezas -una de ellas procedente de la TT 1- y la mano de Guebelein conservadas en Vilanova i la Geltrú. ${ }^{54}$ Como esta última no está incluida en el inventario de las cajas -obviamente, tampoco en el de la venta al MAN, lo que es lógico- cabe la posibilidad de que los tres restos humanos viajaran juntos en la "caixa Vilanova" y no reduzcan aún más la cifra de cráneos. Es además especialmente lamentable que E. Toda no aporte alguna referencia adicional sobre el momento y lugar de adquisición de las cabezas donadas a F. Olóriz. Sin embargo, puede ser significativo que los dos únicos lugares en los que habla de momias en los textos redactados a partir de sus vivencias egipcias, momias cuyos cuerpos se desmoronaron, son la tumba de Sennedjem en Tebas - de la que dice que pudo al menos preservar las cabezas $-{ }^{55}$ y la necrópolis de Guebelein. ${ }^{56}$ Sin embargo, estas referencias son demasiado vagas para poder inferir con seguridad el lugar de hallazgo de los cráneos conservados.

Los periódicos que recogían las entrevistas con Llagostera tras el "descubrimiento" afirmaban que aquella fue la primera momia exhibida en España. ${ }^{57}$ Sin embargo, esa información tampoco es correcta. Un testimonio que sustenta esta crítica resulta paradójico, pues se relaciona indirectamente con el mismo E. Toda. A fines de marzo de 1861, en Reus, la ciudad natal del vicecónsul, se expuso una momia egipcia junto a unos ataúdes con "sus mismas pinturas o jeroglíficos", tal vez los que contuvieron originalmente el cuerpo, y un cosmorama con ocho vistas. No se sabe si E. Toda visitó la exhibición siendo niño. ${ }^{58}$ Como parece difícil que esta escenografía se hiciera para una única ocasión, debió de circular, al menos, por el sur de Cataluña, pero seguramente, en un radio más amplio. Se puede añadir otro ejemplo madrileño, la misma ciudad donde se hizo el desvendamiento, aunque se desconoce $-\mathrm{O}$ al menos no se ha dado a conocer- la fecha en que se le retiraron los vendajes. En 1873 el Estado español compró a Francisco Lameyer el ataúd de Taremetenbastet, hija de Ptahirdis, en el que estaba todavía la momia. El propietario formaba parte del cuerpo administrativo de la Armada y era un conocido pintor orientalista español. Visitó numerosos países de Oriente, algunos, con seguridad, por razones oficiales, pero no se dispone de datos en la actualidad sobre los motivos concretos de su viaje a Egipto. Sin embargo, se tiene la seguridad de que ambos -el ataúd y el cuerpo- fueron adquiridos en El Cairo, pues en el documento de ingreso en el Museo se recoge la mención de los problemas que tuvo el vendedor para sacar las antigüedades de Egipto, todas compradas en su capital, debido a las restricciones impuestas desde la fundación del Museo de Bulaq. ${ }^{59}$ La momia, denominada Madrid V, está actualmente en malas condiciones de conservación debido a un desvendamiento desafortunado. No se tienen noticias de quién lo llevó a cabo ni cuándo, pero el contraste con la conser-

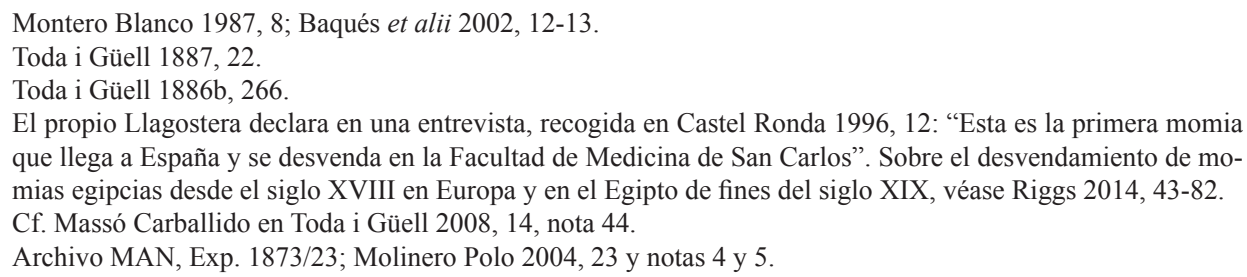


vada en la Universidad Complutense es el mejor testimonio de la pericia con que supo actuar el equipo dirigido por Olóriz en $1886 .{ }^{60}$

Otra afirmación de Llagostera que requiere un comentario es que la momia de San Carlos procedía de Akhmin. ${ }^{61}$ No dice de dónde obtiene ese dato, pero claramente proviene de los inventarios de la colección vendida al MAN. En estos se menciona: ${ }^{62}$

1 / Momia de sacerdote / 21 dinastía / Tebas

1 / Momia de joven (San Carlos) ${ }^{63} / 26$ id. [dinastía] / Ahmim (sic)

Esta entrada indicaría, efectivamente, que la momia de la Facultad de Medicina procedería de Akhmin, pero eso entraría en contradicción con todos los textos escritos por E. Toda. Parece más aceptable que haya habido un error en la adscripción de procedencia en el inventario a que el diplomático se haya equivocado en sus artículos. La primera momia del inventario, la de sacerdote, se corresponde con Madrid I en el catálogo del MAN. Cuando fue radiografiada y analizado el método de momificación, se le dio una cronología de Dinastía XXIII a XXVI, aunque sin explicar las razones. ${ }^{64}$ Podría ser un débil apoyo a la posibilidad de que las referencias estén cruzadas y que la momia de sacerdote sea la que corresponde a Akhmin y la de la joven a Tebas. Por otra parte, la misma procedencia es curiosa, pues E. Toda no estuvo en este yacimiento durante el viaje de inspección al Alto Egipto. Cuando el grupo salía de El Lisht hacia el sur, él tuvo que regresar al norte, a El Cairo, para solucionar problemas administrativos ligados a su permiso y -salvo una visita fugaz a sus compañeros en Asyut para darles noticias- no se reunió de nuevo con ellos hasta que no estaban en Luxor. Eso no impide, naturalmente, que pudiera adquirir alguna antigüedad procedente de ese lugar en otro momento.

La identificación de la momia con una princesa hija de Ramsés II que defendió Llagostera, tenía sentido a partir de la referencia en el acta a Sesostris, que es el nombre que E. Toda da a este rey. Pero no es este monarca el que menciona la prensa a partir de las palabras oídas durante la sesión, sino Ramsés IV. ${ }^{65}$ El mismo diplomático escribía un artículo un mes después explicitando cuál era el origen de la momia: miembro de una familia enterrada en Deir el Medina. E. Toda los califica como "sacerdotes del templo del Ammón tebano, que el rey destinaba a vigilar y guardar el vecino valle [...] donde existían las tumbas reales". ${ }^{66}$ Hoy sabemos que formaban parte del grupo de artistas que decoraban los hipogeos del Valle de los Reyes, pero en las décadas finales del siglo XIX el oficio que desempeñaban aún no se conocía. En definitiva, no hay ningún argumento para calificarla de princesa.

En cuanto a los cartonajes que cubrían la momia y que eran claramente un revestimiento para hacerla más llamativa, resulta necesario entender el contexto concreto en que tuvo lugar el acto. El diplomático había ofrecido la venta de su colección de antigüedades egipcias al Gobierno español en marzo y solo unos días antes de la conferencia, la comisión encargada de valorarla había visitado Barcelona para tasar-

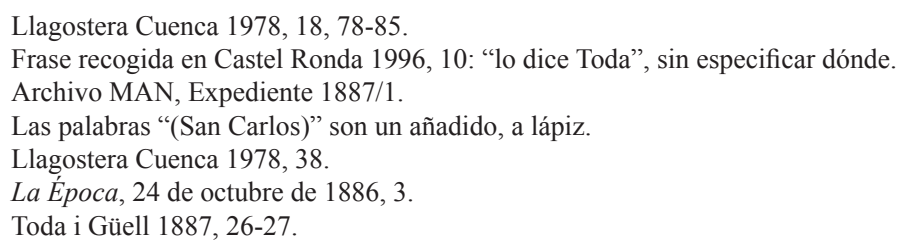


la. El acto le aseguraba una corriente de opinión favorable a la adquisición por el Estado aunque, para entonces, la comisión ya había emitido su informe favorable, firmado el 12 de octubre. ${ }^{67}$ Pero seguramente -incluso por encima del interés económico- había también un cierto deseo de notoriedad pública. Desde su regreso de Egipto a España, la descripción hecha por sí mismo de "sus trabajos" arqueológicos le había dado un cierto protagonismo en los medios culturales. Él era un vicecónsul que acompañaba como amigo a los egiptólogos del Service en algunas de sus salidas de campo -la más notable, el viaje de inspección al Alto Egipto en 1886- mientras que en sus conferencias los verdaderos investigadores se fueron desdibujando, hasta el punto de llegar a hablar de las visitas a los monumentos en primera persona y sin nombrar a los profesionales.

Como si fuera el destino de los que se acercan a esta momia, notoriedad obtuvo también Llagostera cuando decidió darla a conocer. Menos afortunado fue basar la identidad de la persona en lo que él calificó como el acta de la sesión de desvendamiento sin haber sometido el documento a una lectura crítica. No obstante, hay que reconocerle el mérito no solo del estudio radiológico -su especialidad- sino también de haber atraído la atención sobre el testimonio más impactante de la civilización egipcia que se conserva en el patrimonio complutense.

\section{Anexo $^{68}$}

[1] 1) En el curso de 1884 a 1885 siendo decano el Emo. Sr. Don Julián Calleja y Secretario Don Federico Olóriz se verificó una sesión memorable. Se trataba de una conferencia sobre conservación de los cadáveres y sobre las momias recogidas por el agregado diplomático de España en Egipto Sr. Toda.

Este acto se verificó en el gran anfiteatro con asistencia de numerosísimas personalidades científicas y políticas entre ellas el Sr. Ministro de Instrucción Pública y [el] Ministro de Estado.

Se colocó en la mesa de mármol existente en el gran anfiteatro una caja no muy grande de longitud ni anchura, caja de madera de cedro del Líbano con algunos deterioros producidos por la carcoma: caja pintada en colores, un [2] poco apagados sus tonos, en los que predominaban el rojo, el verde y el oro.

El Sr. Toda dio una conferencia verdaderamente interesante y extensa antes de proceder a la apertura del ataúd; sobre la constitución de los terrenos donde enterraban los egipcios, terrenos relativamente altos, secos y arenosos, y en aquellos egipcios de importancia religiosa o de estirpe regia, cómo se practicaba su conservación practicando el embalsamamiento que era distinto según la categoría del muerto y las prácticas que con él se empleaban eran más o menos duraderas pues todas las prácticas de eventración, extracción de la masa encefálica sin apertura del cráneo con instrumentos especiales por las fosas nasales, eran ejecutadas por sacerdotes especiales en [3] 2) estos menesteres, maniobras que iban acompañadas de ritos especiales y actos religiosos que cuando se trataba de un individuo de estirpe regia solían

67 Archivo General de la Administración. Expediente de Eduard Toda i Güell: (5) 1.4 31/06711. No puede saberse por este documento si el diplomático conocía ya, en ese momento, esa conclusión favorable.

68 Los signos de puntuación han sido añadidos por el autor de este artículo, pues son muy escasos en el documento original, lo que dificulta su lectura. La paginación se inicia en la primera hoja escrita, no en la portada. 
durar meses, conferencia sumamente interesante y curiosa que dio el Sr Toda que yo tuve el gusto de oír pues tuve el alto honor de ser designado por el Sr. Decano para ayudar al descubrimiento de la momia al Sr. Toda y al Sr. Doctor Don Federico Olóriz, Catedrático de Anatomía y rentísimo en estudios de Antropología.

Y ahora voy a detallar aunque ligeramente para abreviar lo observado.

Una vez rotos los sellos que cerraban el ataúd y abierto éste pudimos ver y observar que los restos exhalaba[n] un olor balsámico propio [4] de las resinas aromáticas de Oriente que recordaban el olor por todos conocidos del benjuí, el incienso, la mirra, etc., etc. Sobre la momia y cubriendo la cabeza, pecho y abdomen, una cubierta de cartón en colores rojo y verde y dorado, este de un color brillante como acabado de dorar, lo cual indicaba que se trataba de oro puro. Todos estos colores marcaban dibujos especiales muy detallados y de una finura especial que se diferenciaban según la región sobre [la] que fue aplicada la cubierta o mascarilla. Empezando por la extremidad cefálica pudimos ver que la mascarilla era independiente de la inferior o torácica y abdominal. Estaba constituida por una mascarilla que tenía la forma y constitución del tocado de los egipcios que se observa en las esfinges que se aprecian en las pirámides; la cara era de puro oro y lo que imitaba las telas [5] 3) de rayas rojas, verdes y doradas, la parte de la mascarilla que cubría los pabellones auriculares y que estaban dibujados presentaban como arran[can]do de sus lóbulos el dibujo de unos pendientes largos dorados y de dibujos caprichosos. El peto que pudiéramos llamar external en el que predominaba[n] los colores rojo, verde y oro, [con] líneas transversales que simulaban las costillas partiendo del externón, había dibujado gran número de collares y amuletos de distintas formas y dibujos y colocado sobre la primera pieza del externón el escarabeo de oro. Por todos estos detalles, por la magnificencia que representaban los distintos dibujos de collares y amuletos, que daban idea de gran riqueza y una categoría superior de [6] estirpe regia y abolengo religioso y por la traducción de los jeroglíficos egipcios que se observaban, el Sr. Toda deducía que se trataba de una sacerdotisa, hija de Sesostris y por lo tanto princesa egipcia. El peto más inferior y que llegaba a las marcas inguinales estaba constituido por manchas diseminadas uniformes en que predominaba el verde y en el centro una mancha dorada que correspondía por su altura y situación a la cicatriz umbilical. La mascarilla se continuaba cubriendo los miembros abdominales hasta su parte más inferior con las mismas coloraciones, llegando a cubrir el dorso de los pies y afectando la figura total, la que observamos en las bases y cornisas [7] 4) que se observan en los monumentos egipcios. Una vez explicado por el Sr. Toda el significado de esta cubierta o mascarilla total fue quitado y entonces pudimos ver el cadáver momificado y cubierto de un lienzo no uniforme que lo cubría por completo y que solo dejaba al descubierto el rostro. Esta tela de color café con leche oscuro y untuoso al tacto y de olor fuertemente balsámico. Estaba constituido por una serie de bandaletas o vendas de unos 6 o $7 \mathrm{~cm}$ de anchura y de un tejido parecido al de las vendas de Cambri[d]ge hoy usadas. Se fue descubriendo o mejor dicho desvendando la momia y cortando trozos de esta tela que se repartieron entre los concurrentes al acto una vez separado lo que pudiéramos llamar el vendaje (y aquí he de hacer presente una [8] curiosa observación que los extremos de las vendas estaban sujetos por alfileres parecidos a los que hoy se usan para pruebas y antes para sujetar la ropa colgada) una vez como digo separado el vendaje exterior de la momia por encontrarnos que la cubría una tela más fina que la de los vendajes. Un verdadero sudario que solo dejaba al descubierto el óvalo de la cara, que la circundaba y constituía un verdadero tocado. El color de la cara era de un color negro parduzco tal como hoy se aprecia. El paño descrito o sudario estaba adherido a la piel de la momia 
en algunos puntos ahuecados por los dobleces de la tela y de tal manera adherido [9] 5) que cuando se quería arrancar se hacía con la piel quedando en esto que pudiéramos llamar desconchones una superficie de color amarillo papiro. El Sr. Toda hizo observar que esta coloración negruzca del cadáver momificado era debido a la inmersión del cadáver una vez verificada la eventración y extracción de la masa encefálica, en un baño como de asfalto, constituido por una sustancia betunesa en el que predominaba el bálsamo de Judea y que llamaban Natrón.

Este procedimiento de embalsamamiento y conservación egipcio, largo y de gran trabajo, ha sido seguido en cierto modo en los tiempos modernos para anatomizar para conservación de piezas de desecación y por individuos especializados en [10] los embalsamamientos y que daban una seguridad de conservación absoluta y con respecto a este asunto me permito referir al embalsamamiento también por mi practicado, dirigido por mi maestro el sabio erudito eminentísimo catedrático de esta escuela Excmo. Dr. Don Alejandro San Martín en el cadáver del eminente novelista Don Manuel Fernández y González que se verificó en el Ateneo de Madrid. Estuvo sumergido en un baño general por espacio de 12 horas. Extraído del baño se verificó una inyección por ambas femorales de una solución de cloruro de zinc y sublimado corrosivo, inyección a presión hasta ver la replención de los pechos y temporales. Una vez practicada la inyección le vendé con vendas de Cambri[d]ge grueso para las extremidades [11] 6) de vendas de 5x5 para el abdomen y tronco de 10 y 12 centímetros de ancho quedando solamente al descubierto las manos y la cabeza y una vez vendado se le embadurnó con una solución de silicato de potasa a concentración.

Una vez terminada la sesión fue entregada la momia al eminentísimo Catedrático de Anatomía Excmo. Sr. Dr. Don Federico Olóriz, Catedrático que hoy recordamos no solamente como anatómico sino como eminente antropólogo y que a fuerza de trabajo, perseverancia y gran voluntad llegó a constituir un museo con gran número de cráneos perfectamente estudiados, [12] pelados [?], medidos y distribuidos por provincias, estudios tan concienzudos que fueron el fundamento de la Escuela de Criminología de la cual fue Director ya ha bastante antiguo en la Facultad y desempeñando ya el cargo que ocupo y faltando locales para el incremento constante y establecimiento de Especialidades fue preciso trasladar la gran colección de cráneos que poseía el Dr. Olóriz admirablemente catalogados y clasificados por regiones, un verdadero museo, que debió llamarse Instituto Olóriz, traslado que se hizo con gran rapidez en montón [?] y sin sitio donde se hubieran colocado convenientemente, ya que desde mi primera vida estudiantil tuve aficiones anatómicas y en el curso [13] de [mi] vida [de] estudiante continué con mis aficiones quirúrgicas cuya base es la anatomía y en el periodo del Doctorado se instituyó la asignatura de Antropología no obligatoria y cuyo Catedrático fue otro sabio el Dr. Antón de la Facultad de Ciencias cuyas explicaciones cautivaban sobre todo al que como yo tenía esas aficiones innatas que tuve la alta gloria y que aún me vanaglorio de haber sido calificado con la calificación de Sobresaliente. Hice las oposiciones al premio y después de un ejercicio de seis horas de escritura y que lo verificamos dos alumnos se me otorgó el premio y al compañero la mención honorífica y permítaseme esta digresión para hacer constar que me encontré verdaderamente sorprendido al [14] encontrarme con la verdadera riqueza científica que atesoraba el museo del Dr. Olóriz no solo como anatómico sino como patológico y criminológico, ejemplares de lesiones patológicas y lesiones producidas por suplicios y crímenes. Puedo decir que me pasaba las tardes 
en el examen de la recreación de asunto tan interesante que dio lugar a que me llamaran la atención y que me obligasen a desalojar con rapidez el local. Afortunadamente ha venido a suceder al inolvidable Dr. Olóriz, uno de sus discípulos, trabajador infatigable en su época de estudiante en el referido museo de verdadera cepa anatómica el hoy catedrático Dr. Don Julián de la Villa y que como decía anteriormente [15] con cimientos sólidos de anatómico, se halla [sic] construido un edificio quirúrgico acreditado tanto en el Hospital Provincial como en el equipo quirúrgico, Don Julián de la Villa ha recogido lo que ha podido del museo del Dr. Olóriz entre ello la célebre momia que ocupa una de las vitrinas del museo del Dr. Villa situado en el segundo piso del gran anfiteatro museo que encierra una verdadera riqueza de trabajo [siguen seis líneas tachadas e ilegibles]

[16] Entusiasmado con el asunto y con las personas, me he salido del ataúd y de la momia. Sólo diré para terminar que el Dr. Olóriz no solo estudió la momia en cuanto a sus caracteres de talla, edad y medidas antropométricas sino que averiguó la causa ocasional de su muerte. Se trataba de una joven púbera como de 14 a 15 años de edad, mal constituida, con lesiones evidentes de la articulación de la rodilla del lado [hueco] que había padecido una gono artrocace [?] e indudablemente una infección tuberculosa que le originaron la muerte.

\section{Referencias bibliográficas}

Baqués, Ll. - Campillo, D. - Padró, J. - Porta, E. - Xarrié, J. M. (2002): “Les mòmies egípcies del museus catalans i balears", Nilus 9, 3-34.

Castel Ronda, E. (1996): "La hija de Ramsés II. Entrevista con Esteban Llagostera Cuenca", Revista de Arqueología 178, 8-13.

Ikram, S. - Dodson, A. (1998): The Mummy in Ancient Egypt. Equipping the Dead for Eternity, London.

Labajo González, E. - Perea Pérez, B. - Sánchez Sánchez, J. A. - Robledo Acinas, Mª del M. - García Fernández-Hijicos, S. (2011): "Paleopatología dental de siete cabezas egipcias momificadas del Museo de Antropología Forense de la Universidad Complutense de Madrid”, [en] A. González Martín - Ó. Cambra Moo - J. Rascón Pérez - M. Campo Martín - Ma del M. Robledo Acinas - E. Labajo González - J. A. Sánchez Sánchez (eds.), Paleopatología. ciencia multidisciplinar, Madrid, 557-562.

Llagostera Cuenca, E.

(1978): Estudio radiológico de las momias egipcias del Museo Arqueológico Nacional de Madrid, Madrid.

(1995): "The examination of the mummy of a girl in Madrid", [en] C. J. Eyre (ed.), Seventh International Congress of Egyptologists. Abstract of papers, Cambridge, 111.

(1998): "The mummy of a daughter of Ramesses II in Madrid", [en] C. J. Eyre (ed.), Proceedings of the Seventh International Congress of Egyptologists. Cambridge, 3-9 September 1995, Leuven, 691-696.

(2003): "The mummy of a daughter of Ramesses II in Madrid", [en] M. Eldamaty - M. Trad (eds.), Egyptian Museum Collections around the World, Cairo, 733-742.

Luque Talaván, M. (coord.), (2009): Imágenes del Mundo. Enrique de Otal y Ric, diplomático y viajero (=Aragón en los archivos 4 ), Zaragoza.

Mahmoud Abd el Qader, A. (2011): Catalogue of Funerary Objects from the Tomb of the Servant in the Place of Truth Sennedjem (TT1), Le Caire. 
Marcos Alonso, C. - Pons Mellado, E. (1996): "Sobre las falsificaciones egipcias de Tarragona de mediados del siglo XIX”, Boletín del Museo Arqueológico Nacional 14, 157-177.

Molinero Polo, M. Á.

(2004): "El pozo y el péndulo. La actividad egiptológica de anticuarios y arqueólogos españoles, 1868-1966”, [en] A. Martín Flores - Ma V. López Hervás (coords.), Españoles en el Nilo. I. Misiones Arqueológicas en Egipto, Madrid, 15-62.

(2011): "El Egipto antiguo en la controversia académica española del siglo XIX. El discurso de Miguel Morayta en la Universidad Central, octubre de 1884", Bandue. Revista de la Asociación Española de Ciencias de las Religiones 5, 131-150.

(2015): "El Egipto de Eduard Toda en la prensa", [en] N. Castellano - M. Mascort - C. Piedrafita - J. Vivó (eds.), Ex Aegypto lux et sapientia. Homenatge al professor Josep Padró Parcerisa, Barcelona, 399-410.

(2017): "Eduard Toda i Güell en Egipto (1884-1886)", Aula Orientalis 35/2, 291-318.

Molinero Polo, M. Á. - Redondo Villanova, M. (2014): “Tres calcos de relieves asirios en la Biblioteca-Museu Víctor Balaguer”, Butlletí de la Biblioteca Museu Balaguer 7, 99-111. Montero Blanco, T. (1987): Catàleg del Museu Balaguer 2. Col·lecció egípcia, Barcelona.

Pérez Díe, Ma del C. (1996): "Precisiones sobre la existencia en Madrid de una momia egipcia presunta hija de Ramsés II", Revista de Arqueología 182, 6-7.

Reyero, C. (1986): "Las pinturas del Gran Anfiteatro del Colegio de San Carlos en Madrid", Archivo Español de Arte 234, 171-183.

Riggs, Ch. (2014): Unwrapping Ancient Egypt, London.

Saiz Carrero, A. (2009): "Real Colegio de Cirugía de San Carlos", Urología Integrada y de Investigación 14/2, 188-197.

Toda i Güell, E.

(1886a): Sesostris, Madrid.

(1886b): "Las momias egipcias", La ilustración española y americana XLI, 263-267 y 269.

(1887): Son Notém en Tebas. Inventario y textos de un sepulcro egipcio de la XX Dinastía, Madrid.

(1889): A través del Egipto, Madrid.

(1930): El Doctor Joseph Ribera y Sans, Sant Miquel d'Escornalbou.

(2008): Dietari de viatges d'Eduard Toda i Güell, 1876-1891 (amb un apèndix de 1907), Reus (Edició a cura de J. Massó Carballido).

(s.d.): L'antic Egipte. Documentació manuscrita (=Orientalia Barcinonensia 8), Sabadell (Estudi i edició per T. Montero). 